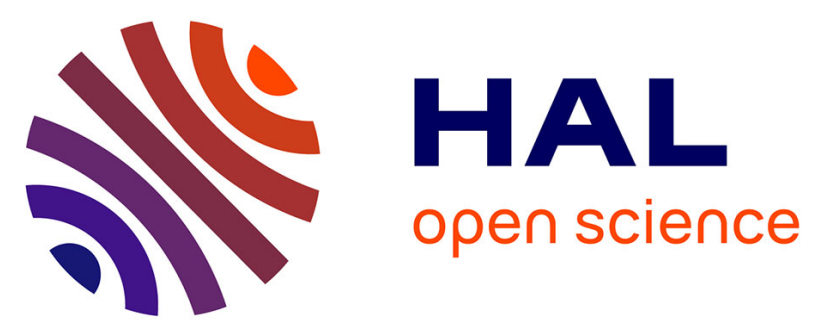

\title{
Gel-to-gel non-variant transition of an organogel caused by polymorphism from nanotubes to crystallites
}

Duncan Schwaller, Samuel Zapién-Castillo, Alain Carvalho, Jérôme Combet,

Dominique Collin, Leandro Jacomine, Patrick Kékicheff, Benoît Heinrich, Jean-Philippe Lamps, Nancy P Díaz- Zavala, et al.

\section{To cite this version:}

Duncan Schwaller, Samuel Zapién-Castillo, Alain Carvalho, Jérôme Combet, Dominique Collin, et al.. Gel-to-gel non-variant transition of an organogel caused by polymorphism from nanotubes to crystallites. Soft Matter, 2021, 17 (16), pp.4386-4394. 10.1039/D1SM00195G . hal-03404659

\section{HAL Id: hal-03404659 \\ https://hal.science/hal-03404659}

Submitted on 26 Oct 2021

HAL is a multi-disciplinary open access archive for the deposit and dissemination of scientific research documents, whether they are published or not. The documents may come from teaching and research institutions in France or abroad, or from public or private research centers.
L'archive ouverte pluridisciplinaire HAL, est destinée au dépôt et à la diffusion de documents scientifiques de niveau recherche, publiés ou non, émanant des établissements d'enseignement et de recherche français ou étrangers, des laboratoires publics ou privés. 


\title{
Gel-to-gel non-variant transition of an organogel caused by poly- morphism from nanotubes to crystallites
}

Received 00th January 20xx, Accepted 00th January 20xx

DOI: $10.1039 / x 0 x \times 00000 x$

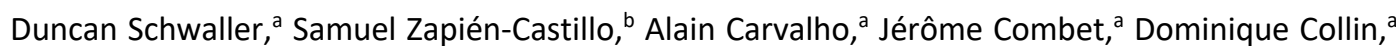
Leandro Jacomine, ${ }^{a}$ Patrick Kékicheff, ${ }^{a}$ Benoît Heinrich, ${ }^{c}$ Jean-Philippe Lamps, ${ }^{a}$ Nancy P. DíazZavala $^{b, *}$ and Philippe J. Mésini ${ }^{a, d},{ }^{*}$

\begin{abstract}
An amide based gelator forms gels in trans-decalin. Below concentrations of $1 \mathrm{wt}$ \% the gels melt at temperatures varying with concentration. Above concentration of $1 \mathrm{wt}$. \%, upon heating, the gel transforms into an opaque gel at an invariant temperature, and melts at higher temperature. The gel-to-gel transition is evidenced by several techniques: DSC, rheology, NMR, OM and turbidimetry. The phase diagram with the domain of existence of both morphs was mapped by these techniques. Optical and electronic microscopy studies show that the first gel corresponds to the self-assembled nanotubes while the second gel is formed by crystalline fibers. The fibers are crystalline, as shown by the presence of Bragg peaks in the scattering curves. Both morphs correspond to a different H-bonding pattern as shown by FTIR. The first gel forms at higher cooling rate, is metastable and transforms slowly into the second one. The second gel is the stable form. It forms at low cooling rate, or by thermal annealing or aging of the first gel.
\end{abstract}

\section{Introduction}

Low molecular weight gelators are a class of molecules able to gel solvents at low concentration. ${ }^{1-3}$ Their study has expanded in the last decades and they now constitute a large library of compounds. Most of the effort has been devoted to the synthesis of new gelators with the aim to develop their applications, ${ }^{4}$ for instance in biomedical field ${ }^{5}$ or in organic electronics. ${ }^{6}$ But many fundamental aspects of organogelators are still unknown. ${ }^{7}$ The most conspicuous one is the absence of rules to predict if a compound will be able to form gel. These rules will necessitate to correlate the chemical structures of the gelators with their efficiency and the stability of the formed gels. In this task, phase diagrams are essential tools, because they allow to compare quantitatively these properties in a large range of concentrations. They also provide the experimental validity when gelation ability is correlated with solubility parameters. ${ }^{8-12}$ For instance, Feng and Cavicchi ${ }^{13}$ could test a regular solution model and Kamlet-Taft parameters on the full phase diagram of triamides organogelators. The phase diagram can also explain different mechanisms of gelation, and hence different gel

\footnotetext{
a. Université de Strasbourg, CNRS, Institut Charles Sadron, 23 rue du Loess, F-67000 Strasbourg France.

b. Tecnológico Nacional de México-Instituto Tecnológico de Ciudad Madero, Centro de Investigación en Petroquímica. Prolongación Bahía de Aldair, Ave. de las Bahías, Parque de la Pequeña y Mediana Industria, 89600 Altamira, México. c. Institut de Physique et Chimie des Matériaux de Strasbourg (IPCMS), UMR 7504 CNRS-Université de Strasbourg, 23 rue du Loess, 67037 Strasbourg Cedex 08, France.

d. International Center for Frontier Research in Chemistry, 8 allée Gaspard Monge, 67000 Strasbourg, France.

*corresponding authors: nancy.dz@cdmadero.tecnm.mx,

mesini@ics-cnrs.unistra.fr
}

morphologies. It is commonly admitted that the phase diagrams of organogelators have only two domains: sol and gel. But we showed that it can also comprise miscibility gaps in the sol, leading to two kinds of gel formation: a regular sol-gel transition (where $T$ varies with $c$ ) and a monotectic transition (where $T$ is invariant) forming the gel from a liquid-liquid biphasic mixture. ${ }^{14}$ The existence of a plateau in some other systems suggests that miscibility gaps are not unusual. ${ }^{15,16}$ Phase diagrams are also more complex when organogelators show polymorphism, which is frequent. The most visible manifestation of this trend is the formation of crystallites along with gelation or upon ageing samples. ${ }^{17}$ In some cases only one of the morphs forms gels and in other cases, two different morphs form gels with different morphologies and rheological properties. ${ }^{18-21}$ The direction toward one form or the other is influenced by the temperature of formation of the ge $\mathrm{l}^{18,19}$ and the rate of cooling. ${ }^{22}$ sometimes one observes a thermodynamical and reversible transition between two morphs, each one forming a distinct gel. $^{20,21,23}$ Xie et al. have evidenced a transition between solid fibers to worm-like micelles. ${ }^{20}$ Transition between two fibrillar structures have been observed by Kotlewski et al. for a discotic liquid crystal gelator ${ }^{21}$ and by Meister et al. for a bolaamphiphilic gelator..$^{23}$ In these examples, the transitions occur from gel to gel and identified by a change in the elastic modulus and an exothermic peak in differential scanning calorimetry (DSC). ${ }^{23}$ These studies do not map these transitions within a phase diagram. However, the nature of these transitions and the relations between the different morphs can be better understood thanks to diagrams. Such transitions, just by their presence, should give the diagrams a more complex aspect than generally accepted for gelators. They may display the same diversity as in other fields, like polymer science ${ }^{24}$ or metallurgy. ${ }^{25}$ 


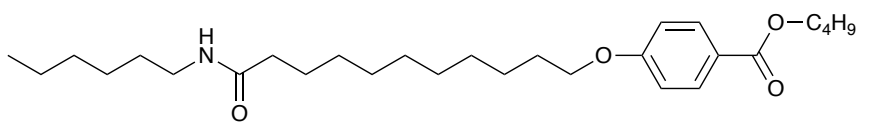

Figure 1. Structure of HUB-4

In this paper we study a monoamide gelator, HUB-4 (Fig. 1) exhibiting a polymorphism and a gel-to-gel transition. We have previously found that in cyclohexane, HUB-4 forms gel at concentration of $1 \mathrm{wt} . \%$. In these gels, the aggregates are nanotubules as observed by transmission electron microscopy (TEM) and small angle X-ray scattering (SAXS). ${ }^{26}$ Herein we show that for given temperatures and concentrations, they transform into aggregates of different shapes. We have studied the nature and the characteristics of this transformation by different techniques: quantitative VT-NMR, rheology and turbidimetry. We have mapped the $c-T$ phase diagram of the gelator comprising this transition, and compared the relationship between both forms.

\section{Materials and methods}

Materials. HUB-4 was synthesized following a described procedure. ${ }^{26}$ trans-Decalin (TD) was purchased from $\mathrm{TCl}$ Chemicals and purified by filtration on a column of silica.

Mechanical measurements. The real and imaginary parts of the complex shear modulus were measured in the oscillatory mode with commercial stress-controlled rheometers, Haake, Mars III with a Couette cell or a TA instruments, DHR-3 in cone-plate geometry. These apparatuses apply a torque (i.e., a stress) and measure the strain transmitted through the sample.

The temperature was regulated by a heating bath and controlled between 5 and $95{ }^{\circ} \mathrm{C}$, within $\pm 0.05^{\circ} \mathrm{C}$. The experiments consisted in following the evolution of the complex shear at a given frequency, when temperature was progressively decreased or increased between 75 to $20{ }^{\circ} \mathrm{C}$ at a rate of $0.25^{\circ} \mathrm{C} / \mathrm{min}$. For all shear measurements, the applied stress was $5 \times 10^{-2} \mathrm{~Pa}$ to ensure the data belong in the linear response regime. The thickness of the samples was $\sim 400 \mu \mathrm{m}$ for the Couette cell.

Prior to sample measurements, a blank experiment was conducted without the sample to know the residual stress, in phase with the strain, related to the experimental limit of the device. This residual stress has been subtracted from the rheological measurements presented in this study.

Differential Scanning Calorimetry (DSC). The thermograms were recorded with a MC-DSC (TA instrument). The measuring cells were filled with HUB-4 (between 1.7 and $13.2 \mathrm{mg}$ ). transDecalin was added in the cells to obtain the defined weight concentration of HUB-4. The final weights of the sample were about $330 \mathrm{mg}$. The reference cell was filled only with trans-decalin. The full cells had equal weights within a deviation of $5 \mathrm{mg}$. The gels were formed during a first cycle (heating at $1{ }^{\circ} \mathrm{C} / \mathrm{min}$ and cooling at a, imposed rate, varying with the experiments between 1 and $0.25{ }^{\circ} \mathrm{C} / \mathrm{min}$ ). The presented thermograms were measured during a second cycle at $0.25^{\circ} \mathrm{C} / \mathrm{min}$.
Turbidimetry measurements. The turbidity of the samples at different temperatures was followed by the light intensity transmitted through the sample with a home-made optical device. A monochromatic light beam $(\lambda=632.8 \mathrm{~nm})$, provided by a HeNe laser (Melles Griot 05-LHP-151), successively went through an attenuating filter $\left(10^{-3}\right)$, a pinhole $(50 \mu \mathrm{m})$, the sample $(5 \mathrm{~mm}$ patway), and a second pinhole $(150 \mu \mathrm{m})$. At the end, the beam was focused onto the objective of a CCD camera (Retiga 2000R) to measure its intensity. The light intensity was measured while temperature was decreased from 75 to $20^{\circ} \mathrm{C}$ or increased from 20 to $75{ }^{\circ} \mathrm{C}$ at a constant and imposed rate. Typical exposure times were in the range of 500-2000 ms. The sample temperature was controlled by an oven driven by a PID controller (SHINKO 100).

Optical Microscopy. The solutions were observed and characterized with an optical microscope Olympus BX51, equipped with a Nikon DXM 1200 camera. The studied mixtures were first heated and homogenized into the isotropic phase in an oven. Rectangular capillaries (CM Scientific, $0.5 \mathrm{~mm} \times 2 \mathrm{~mm}$ ) were filled with this solution by capillarity and sealed with a blowtorch. The capillaries were then placed in a hot stage regulated at $\pm 0.1{ }^{\circ} \mathrm{C}$ and observed in bright-field microscopy. The phase changes under cooling and heating were determined at a rate of $0.3^{\circ} \mathrm{C} / \mathrm{min}$. Some samples were formed at high cooling rate by quenching the heated capillary in cold water.

Fourier transform infrared (FTIR). Mid-IR spectra of the samples were measured as a function of temperature between 25 and $75^{\circ} \mathrm{C}$ with a Bruker Vertex 70 spectrometer using a mercury cadmium telluride detector, a $\mathrm{KBr}$ beam splitter, and a blackbody source. The spectral resolution was $2 \mathrm{~cm}^{-1}$, and 64 scans were coadded for each spectrum. The liquid cell was filled with a weight fraction of $4 \mathrm{wt}$. \% HUB-4 in trans-decalin. The macroscopic gel formation was studied in a home-made liquid cell equipped with two $\mathrm{NaCl}$ windows spaced by an indium flat $\mathrm{O}$ ring. The cell was inserted in a thermoregulated Linkam heating stage. The cooling or heating rate was the same as for DSC experiments.

Nuclear Magnetic Resonance (NMR). The NMR experiments were performed on a Bruker Avance III HD spectrometer equipped with a $5 \mathrm{~mm}$ BBO type probe. HUB-4 (8.85 mg), transdecalin-d18 (489 mg, Cambridge Isotope Laboratories), and bis(trimethylsilyl)acetylene ( $\mathrm{TCl}$ ) were introduced in an NMR tube. The tube was sealed, heated, and shaken until complete dissolution and allowed to cool at RT to form a gel. The cooling rate was higher than $5{ }^{\circ} \mathrm{C} / \mathrm{min}$. The spectra were recorded every $2{ }^{\circ} \mathrm{C}$ from $298 \mathrm{~K}$ to $348 \mathrm{~K}$. At every step, the sample was stabilized for $5 \mathrm{~min}$ to obtain the desired temperature. Each measurement took $20 \mathrm{~min} 28 \mathrm{sec}$ ( $32 \mathrm{scans}, 30 \mathrm{sec}$ relaxation time). The intensities of the spectra $\left(I_{\mathrm{p}}\right)$ were first normalized with those of bis(trimethylsilyl)acetylene $\left(I_{\mathrm{st}}\right)$ as an internal standard $\left(I=I_{\mathrm{p}} / I_{\text {st }}\right)$. For a given peak, the intensities $I$ increase with temperature and reach a plateau $I_{\max }$ at $55^{\circ} \mathrm{C}$ corresponding to the sol (i. e. full dissolution of the gelator). The normalized $/$ values were then converted to the concentration $c$ of gelator in the liquid phase according to Eq. 1.27 


$$
c=c_{t} \frac{I}{I_{\max }} r /\left[1+c_{t}\left(\frac{I}{I_{\max }} r-1\right)\right]
$$

where $c_{\mathrm{t}}$ is the total concentration of the gelator. $r$ is the ratio of the densities of the deuterated to the protonated solvent $(r$ $=1.15)$. $r$ is introduced to convert concentration in deuterated solvent to the concentration of the solution in protonated with the same volume fraction.

Scanning electron microscopy (SEM). A piece of gel placed onto a cryo-holder was quickly plunged into a nitrogen slush and subsequently transferred under vacuum into the Quorum PT 3010 chamber attached to the microscope. There, the frozen sample was fractured with a razor blade and etched at $-70{ }^{\circ} \mathrm{C}$ to reveal the details of the morphology. The sample was eventually transferred in the FEG-cryo SEM (Hitachi SU8010) and observed at $1 \mathrm{kV}$ at $-150^{\circ} \mathrm{C}$.

X-ray scattering experiments were performed on both desktopgenerated and synchrotron X-rays. For the former, we used a Rigaku diffractometer using a microfocus rotating anode generator (Micromax ${ }^{\mathrm{TM}}-007 \mathrm{HF}, 40 \mathrm{kV}, 30 \mathrm{~mA}$ ). A monochromatic and focused $X$-ray beam $\left(\lambda=1.54 \AA\right.$ with $\Delta \lambda / \lambda<4 \% ; K_{\alpha}$ emission of $\mathrm{Cu})$ is obtained through a confocal Max-Flux OpticsTM mirror (Osmics) The three pinholes collimation system lowers the beam divergence. In addition, the sample cross-section irradiated by the incident beam is close to $600 \mu \mathrm{m}$, resulting in a good in-plane resolution function with a half-width at half maximum of the order of $7 \times 10^{-3} \AA^{-1}$ (value calibrated by the diffraction on tricosane). The scattered intensity was collected with two configurations covering $q$ values from 0.011 to $1.9 \AA^{-1}$ ( $q$ is defined as $(4 \pi / \lambda) \sin \theta$ where $2 \theta$ is the scattering angle). SAXS data were measured with a 2D multiwire detector located at $81 \mathrm{~cm}$ from the sample $\left(0.011<q<0.33 \AA^{-1}\right)$. The wide-angle $X$-ray scattering (WAXS) data were recorded on Fuji imaging plates inserted at $20 \mathrm{~cm}\left(0.1 \AA^{-1}<\mathrm{q}<1.90 \AA^{-1}\right)$. To determine the crystalline structure precisely, WAXS was also performed on the SIRIUS beamline at the French National Synchrotron Radiation Facility SOLEIL in Saint-Aubin, France. ${ }^{28}$ An X-ray energy of $10 \mathrm{keV}$ (Xray wavelength $\lambda=1.24 \AA$ ) was selected with a Si(111) double crystals monochromator. Two-dimensional $\mathrm{X}$-ray scattering data were collected on a DECTRIS PILATUS3 1M 2D detector positioned $472 \mathrm{~mm}$ downstream of the sample. The sample-to-detector distance was calibrated by the diffraction pattern of silver behenate. The $q$-range was from 0.10 to $3 \AA^{-1}$ with an in-plane resolution of about $2 \times 10^{-3} \AA^{-1}$.

The gel at $2 \%$ was inserted in a home-made cell with two calibrated mica sheets windows 1 or $0.5 \mathrm{~mm}$ apart. It was heated to $70{ }^{\circ} \mathrm{C}$ during $15 \mathrm{~min}$ until complete dissolution and quickly cooled in a bath of water and ice. The reformed gel was rapidly introduced into a home-made oven in the diffractometer and measured by SAXS (1000 s) and WAXS (7200 s) at a temperature of $10{ }^{\circ} \mathrm{C}$. The temperature is then increased to $45{ }^{\circ} \mathrm{C}$ for two hours before repeating SAXS and WAXS measurements. On the SIRIUS beamline, the WAXS patterns were collected as a function of temperature from room temperature to $60^{\circ} \mathrm{C}$. The heating rate was $0.2{ }^{\circ} \mathrm{C} / \mathrm{min}$ and a $10 \mathrm{~min}$ temperature stabilisation was allowed for the WAXS pattern to be recorded at every chosen temperature along the range ( $\sim \mathrm{h}$ experiment for a range 23-60 ${ }^{\circ} \mathrm{C}$ ). The signal was corrected and treated as previously described. ${ }^{26}$

\section{Results and Discussion}

\section{Techniques of study of the transitions.}

Samples at different concentrations were heated from RT to $75^{\circ} \mathrm{C}$. at a controlled rate. Their phase behaviour was followed by different techniques: differential scanning calorimetry, mechanical measurements, optical microscopy (OM), turbidimetry and NMR. In a first series of experiments, the gels were formed at high cooling rates and measured shortly after formation. They were formed in situ at the same controlled rate of 1 ${ }^{\circ} \mathrm{C} / \mathrm{min}$. For some experiments (OM or $\mathrm{NMR}$ ) such control or rate were not technically possible and the gels were prepared at higher cooling rate $\left(>5^{\circ} \mathrm{C} / \mathrm{min}\right)$. For the measurements, the heating rate was fixed to $0.25^{\circ} \mathrm{C} / \mathrm{min}$ for all techniques except for optical microscopy $\left(0.3^{\circ} \mathrm{C} / \mathrm{min}\right)$.

Figure 2 shows the different measurements on a sample of concentration $0.5 \mathrm{wt}$. \%. The mechanical measurements consisted in measuring the elastic and viscous moduli when the temperature increased. Below $33^{\circ} \mathrm{C}$ the sample shows a solid-like behaviour with $G^{\prime}>G^{\prime \prime}$. Around $33^{\circ} \mathrm{C}$, both curves decrease, cross over, and eventually switch with $G^{\prime}<G^{\prime \prime}$, characterising a liquidlike behaviour. The temperature of the sol-to-gel transition is defined by the temperature at which the curves cross over ( $T_{\mathrm{GS}}$ $=34.3{ }^{\circ} \mathrm{C}$, for $\mathrm{C}=0.5 \mathrm{wt} . \%$ ).

Turbidimetry consists in measuring the light transmitted through the sample. Since gels usually contain heterogeneities or large enough aggregates, they scatter more intensity than the sol. The increase in transmitted intensity when temperature varies indicates the temperature of the gel-sol transition. This technique has been implemented by us ${ }^{14,27}$ and Devergnes ${ }^{29,30}$ to map phase diagrams. For sample at $c=0.5 \mathrm{wt}$. \%, the transmitted intensity is low at room temperature and increases with $T$. It reaches a plateau at $31^{\circ} \mathrm{C}$ that correspond to the sol, which is homogeneous and contains no large aggregates.

The DSC shows an endotherm with a maximum at $31.2^{\circ} \mathrm{C}$. This endotherm represents the enthalpic changes accompanying the dissociation of the compound when $T$ increases. The full dissolution corresponds to the inflection point at $33.1^{\circ} \mathrm{C}$. All the techniques measure the same temperature of transition within $3^{\circ} \mathrm{C}$. However, only the mechanical experiment measures the real

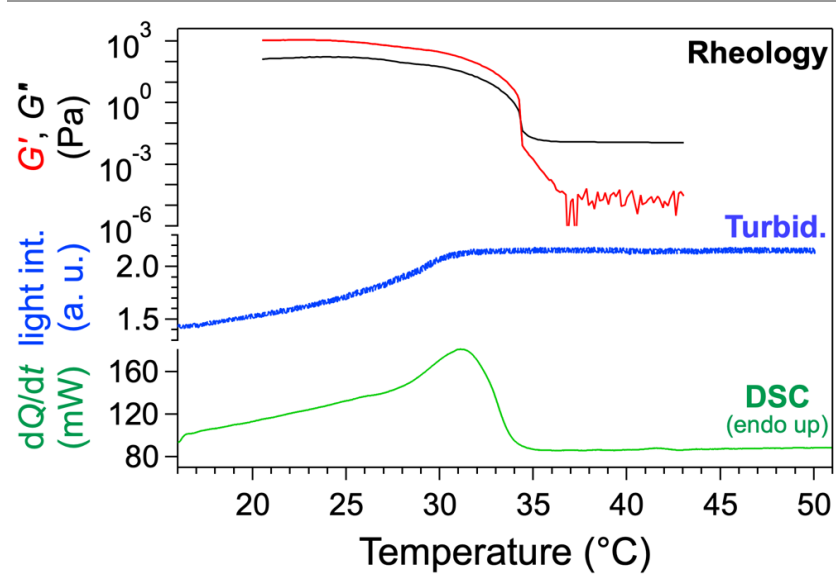

Figure 2. Variations of different quantities of the HUB-4/trans-decalin gels at $c=0.5 \mathrm{wt}$. \% when heated at $0.25{ }^{\circ} \mathrm{C} / \mathrm{min}$. The gels were formed at cooling rates of 1 ${ }^{\circ} \mathrm{C} / \mathrm{min}$ and let rest less than $70 \mathrm{~min}$ before measurement. 


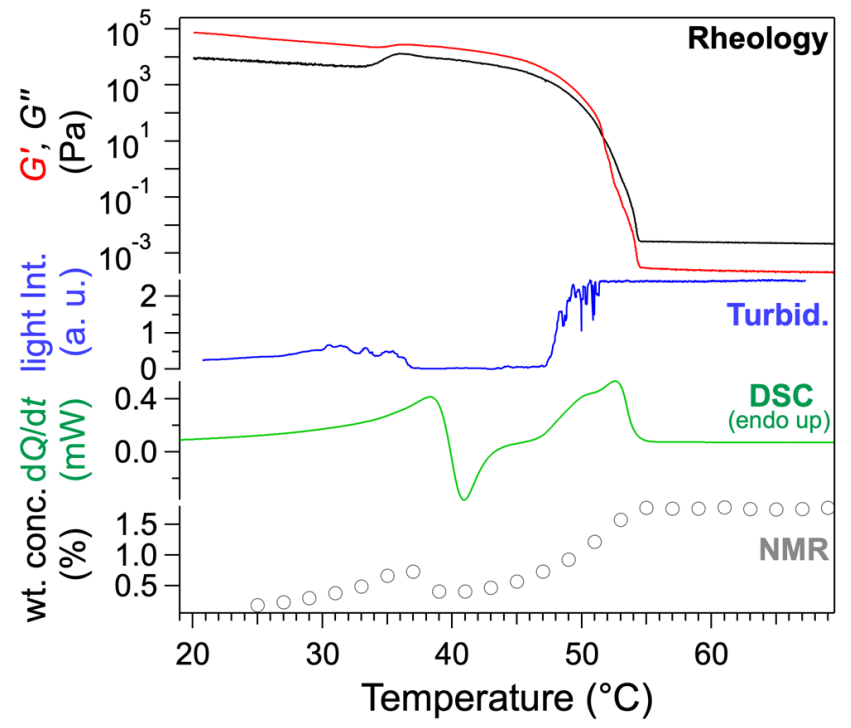

Figure 3. Variations of different quantities of the HUB-4/trans-decalin mixture. The molar fraction of HUB4 is 0.006 for all samples, corresponding to $2 \mathrm{wt}$. \% in protonated trans-decalin and $1.77 \%$ in D18-trans-decalin (NMR). The heating rate is $0.25{ }^{\circ} \mathrm{C} / \mathrm{min}$. The gels were formed at cooling rates of $1^{\circ} \mathrm{C} / \mathrm{min}$ or higher and let rest less than $70 \mathrm{~min}$ before measurements.

$T_{\mathrm{GS}}$, since the gel-to-sol transition is defined by a change in mechanical behavior. DSC measures a thermodynamic event associated with this transition: the full solubilization of the gelator in the liquid phase.

\section{Identification of gel-to-gel transitions for $c>1$ wt. \%.}

The same experiments have been carried out for different concentrations. At low concentration the results are easy to explain, but for $\mathrm{c}>1 \mathrm{wt}$. \%, their interpretation become more complex. Figure 3 shows the measurements on a sample at a concentration of $2 \mathrm{wt} . \%$ and a heating rate of $0.25^{\circ} \mathrm{C} / \mathrm{min}$. The crossover of $G^{\prime}$ and $G^{\prime \prime}$ provides a value of $T_{G S}=51.6^{\circ} \mathrm{C}$. The mechanical curves show another event around $35^{\circ} \mathrm{C}$ : both $G^{\prime}$ and $G^{\prime \prime}$ increase while $G^{\prime}$ remains higher than $G^{\prime \prime}$, which corresponds to the evolution of a gel to a stronger gel. For concentrations close to $1 \mathrm{wt}$. \% and for slower formation rates and slower heating rate this new transition can be visualized more clearly by a decrease followed by an immediate increase of the

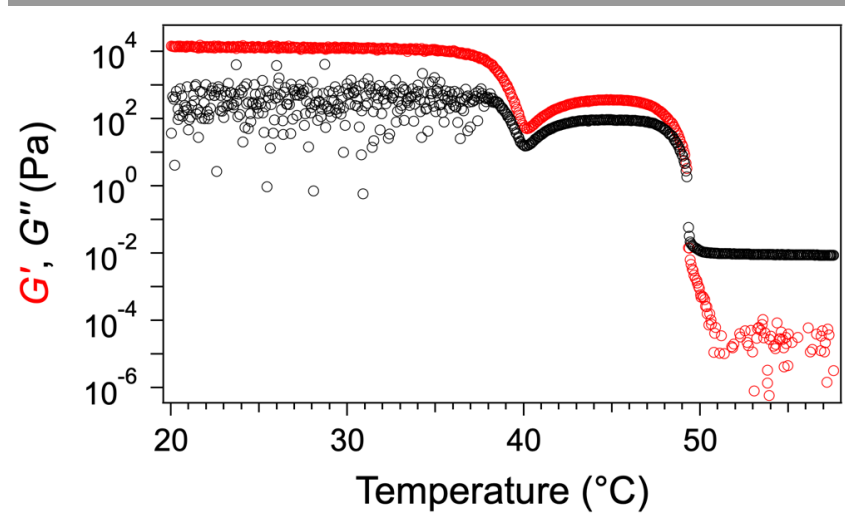

Figure 4. Elastic and viscous moduli of a HUB-4/trans-decalin gel (1.3 wt. \%) as a function of $T$ (heating rate $0.1^{\circ} \mathrm{C} / \mathrm{min}$ ). The gel was formed at a cooling rate of $0.1^{\circ} \mathrm{C} / \mathrm{min}$. moduli (Fig. 4). The relative values of the storage modulus will be discussed later in the light of the structural studies. The thermograms also are more complex at higher than lower concentrations. For $c=2$ wt. \% (Fig. 3), as $T$ increases, it shows an endotherm ( $\max$. at $38.3{ }^{\circ} \mathrm{C}$ ) immediately followed by an exotherm ( $\mathrm{min}$. at $40.9{ }^{\circ} \mathrm{C}$ ). When $T$ further in-creases, a second endotherm appears $\left(\max .52 .6^{\circ} \mathrm{C}\right)$. Its maxi-mum, at $52.6^{\circ} \mathrm{C}$ is close to the transition temperature $T_{\mathrm{GS}}$ measured by rheology. Therefore, the last endotherm corresponds to the gel-to-sol transition. The first two events can be interpreted in the light of the mechanical behaviour observed around $35{ }^{\circ} \mathrm{C}$. The first endotherm corresponds to the beginning melting of a solid phase, and the following exotherm, to its subsequent crystallization into another solid phase. The temperature between both, when the heat flow crosses the baseline is taken as the temperature of the solid-to-solid transition $\left(39.7^{\circ} \mathrm{C}\right)$. The melting temperature of the gel is taken as the inflection point at the end of the second endotherm $\left(53.5^{\circ} \mathrm{C}\right)$.

The turbidimetry experiments also show two events. In the first one, the light intensity increases progressively up to $31{ }^{\circ} \mathrm{C}$ and then shows a series of irregularities up to $37^{\circ} \mathrm{C}$, and eventually decreases. In the second event, the transmitted intensity finally increases and reaches its maximum at $51.6^{\circ} \mathrm{C}$. This maximum corresponds to the solution, which is homogeneous and contains no longer aggregates scattering light. For the first event, the intensity decreases at the same temperature as the first transition observed by DSC, and reaches its plateau at the maximum of the DSC endotherm, within $2{ }^{\circ} \mathrm{C}$. The decrease in intensity at $37^{\circ} \mathrm{C}$ and its low values between 37 and $48^{\circ} \mathrm{C}$ correspond to an increase of opacity. This is visualized more simply in a tube standing on a hot plate at $45{ }^{\circ} \mathrm{C}$, in which a thermal gradient appears (Fig. 5, left). The bottom of the vial, warmer, is white and opaque, while the top of the tube, cooler, is more transparent. By optical microscopy (OM), one observes between 25 and $43^{\circ} \mathrm{C}$ a speckled texture with no visible crystallites (Fig. 5, right). When the sample is heated, long fibrils grow and eventually fill the sample. This transition corresponds to the first transition observed in turbidimetry and DSC. The fibres grow across from along a frontline, which shows a nucleation-growth mechanism.
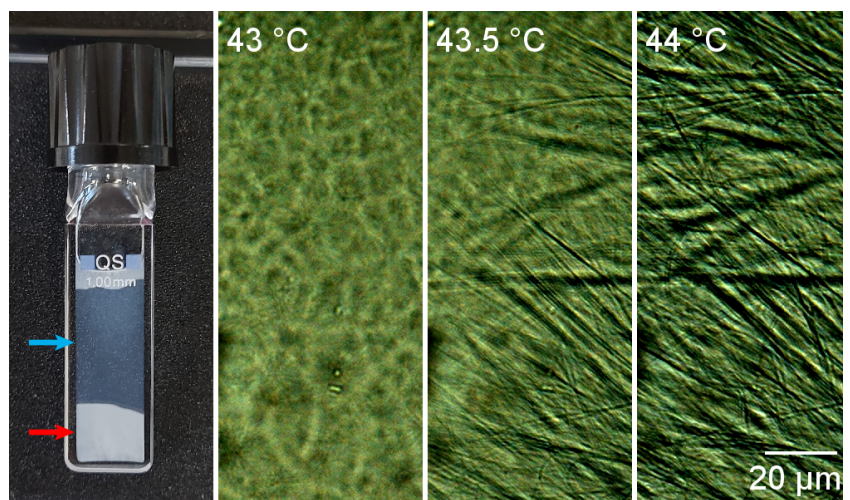

Figure 5. Left: aspect of a vial standing on a plate at $45^{\circ} \mathrm{C}$. The bottom area (red arrow) is warmer than the top area (blue arrow) and is opaque. Both areas are gels. Right: optical micrographs of a sample of HUB-4/trans-decalin, below and above transition. The initial gel was formed at cooling rate higher than $5^{\circ} \mathrm{C} / \mathrm{min}$ and let rest less than $1 \mathrm{~h}$. 


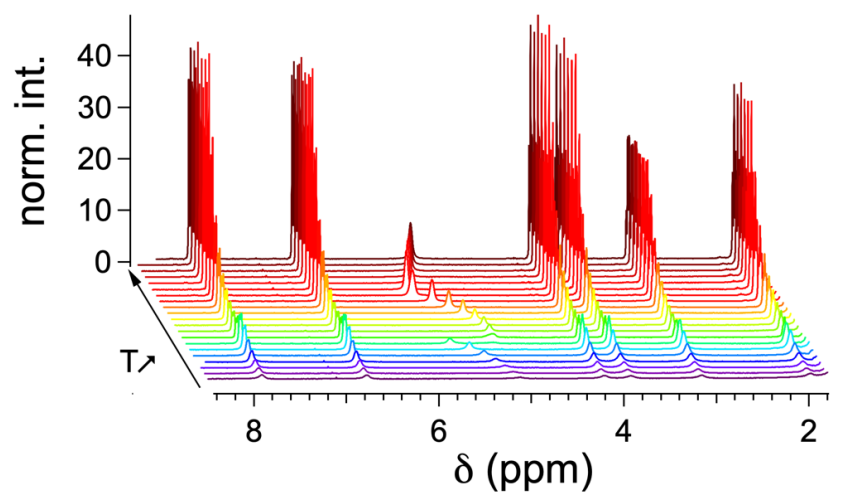

Figure 6. NMR Spectra of HUB-4 in TD (1.77 wt. \%), from 25 to $65^{\circ} \mathrm{C}$. The intensities are normalized with an internal standard. Interpretation of the spectrum at $55^{\circ} \mathrm{C}: 400 \mathrm{MHz}$ $2.02\left(\mathrm{t}, J=7.6 \mathrm{~Hz}, 2 \mathrm{H}, \mathrm{NHCOCH}_{2}\right), 3.15\left(\mathrm{q}, J=6.6 \mathrm{~Hz}, 2 \mathrm{H}, \mathrm{CONHCH}_{2}\right), 3.93(\mathrm{t}, J=6.6 \mathrm{~Hz}$, $\left.2 \mathrm{H}, \mathrm{ArOCH}_{2}\right), 4.21\left(\mathrm{t}, J=6.6 \mathrm{~Hz}, 2 \mathrm{H}, \mathrm{COOCH}_{2}\right), 5.75(\mathrm{~s}, 1 \mathrm{H}, \mathrm{NH}), 6.78(\mathrm{~d}, J=8.9 \mathrm{~Hz}, 2 \mathrm{H}$, ArC3-H, ArC5-H), 7.9 (d, J = 8.9 Hz, $2 \mathrm{H}, \mathrm{C} 2-\mathrm{H}, \mathrm{C} 6-\mathrm{H}, \mathrm{COO}-(\mathrm{Ar}) \mathrm{CCH})$. The normalized integrals are reported in Figure 3 (bottom) and in phase diagram (Fig. 7).

The transition is observed at higher temperature by OM than by turbidimetry because the growth starts from a lower number of nuclei in the smaller volume of the capillary than in the large volume of the turbidimetric experiments and propagates slowly through the sample. ${ }^{14}$

For the concentration of $2 \mathrm{wt}$. \%, we have also studied the transitions by quantitative NMR. Since NMR uses deuterated solvent the wt. conc. has been chosen to match the volume fraction of the other experiments, using protonated solvent $(0.006$, equivalent to $1.77 \mathrm{wt}$. \% in d18-TD). The spectra are measured when the temperature increases and their intensities normalized to the intensity of an internal standard (Fig. 6). The intensities of the protons of the compound vary with $T$, and reach a plateau once the gelator is fully dissolved in the sol. The temperature at which the plateau starts has been used in the literature as a measurement of $T_{\mathrm{GS}}{ }^{27,31}$ As shown in our previous work, ${ }^{27}$ below the plateau, the intensities of the signals are proportional to the concentration of the gelator in the liquid phase but the rest of the gelator, in the solid phase, is silent. When suitably normalized, the ascending branch of the curve represents the sol/gel boundary in a phase diagram. For this reason, it is important to present these measurements to corroborate the aspect of the phase diagram. The variations of the NMR intensities as a function of $T$ (Fig. 3, bottom), present an aspect close to that of DSC, with a slow increase up to $37^{\circ} \mathrm{C}$ and a consecutive decrease. This aspect means that as the gel is heated up to $37^{\circ} \mathrm{C}$, part of the gelator solubilizes. Then, at $37^{\circ} \mathrm{C}$, part of the solubilized gelator returns to the solid phase. It shows that under $37^{\circ} \mathrm{C}$ the sol was supersaturated. Above $40^{\circ} \mathrm{C}$, the intensity slowly increases, until it reaches the plateau at $55^{\circ} \mathrm{C}$. This second part of the curve has the classical aspect: the soluble part of the gelators increases with $T$ and reaches a plateau when the gel melts and all the gelator is in the sol. The shifts of the peak between 5 and $6 \mathrm{ppm}$, attributed to the amide proton shows a similar evolution, especially a maximum at $37^{\circ} \mathrm{C}$.

\section{Phase diagram.}

These measurements have been repeated for different concen-

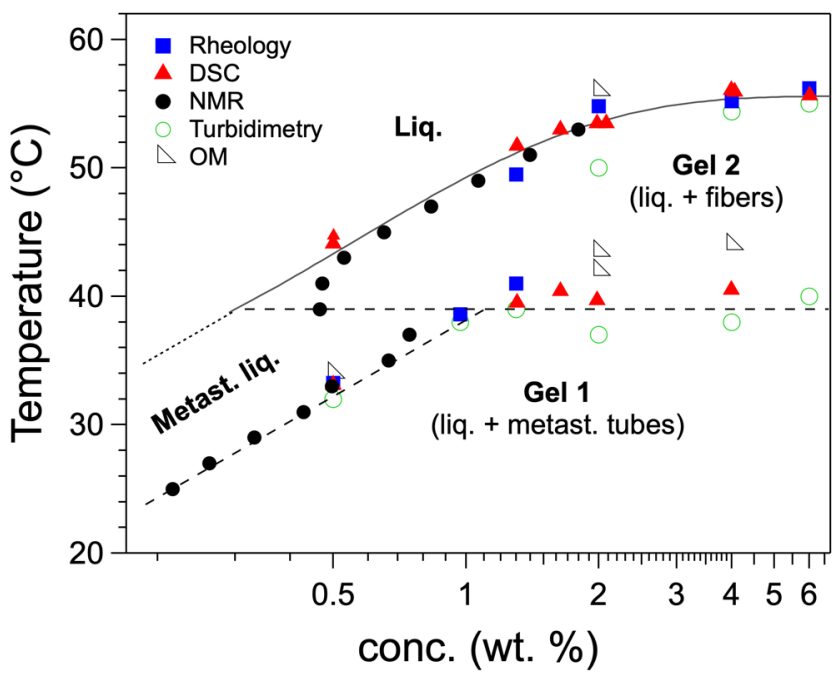

Figure 7. $c$ - $T$ phase diagram of HUB4/trans-decalin; heating rate is $0.25^{\circ} \mathrm{C} / \mathrm{min}$ for all the experiments except $\mathrm{OM}\left(0.3^{\circ} \mathrm{C} / \mathrm{min}\right)$. The results of DSC at $0.10^{\circ} \mathrm{C} / \mathrm{min}$ have been added. Plain lines: limit between the gel existing above $39^{\circ} \mathrm{C}$ and the sol. Horizontal dashed line transformation solid 1 to solid 2 at $0.25^{\circ} \mathrm{C} / \mathrm{min}$. The plain and dotted lines correspond to the liquidus of gel 2 ; the oblique dashed line to the liquidus of gel 1.

trations between 0.2 and $6 \%$, covering more than one decade. As we have previously shown, ${ }^{14}$ a large $c$-range allows to detect different types of transition in organogels and hence different mechanisms of formation.

For concentrations below 1 wt. \%, the OM and turbidimetric experiments detect only one transition. The lower saturation concentrations calculated from NMR, superimpose with these transitions. This line in the diagram starts at low $c$ and $T$ and stops at $\sim 1 \mathrm{wt}$. $\%$ and $39^{\circ} \mathrm{C}$. For concentrations above this threshold, the samples show two transitions. The first one at $39^{\circ} \mathrm{C}$, before the gel transforms into sol. This event is observed from DSC, turbidimetry and NMR experiments, at the same temperature within a few degrees. In rheology, change in elasticity is not always visible, but $G^{\prime}$ remains greater than $G^{\prime \prime}$, which shows that the sample is a gel below and above this transition. Therefore, this transition is assigned to a transformation of the solid fraction in the first gel to another solid fraction in the second gel. The temperature of this transition does not depend on concentration. This non-variance can be explained according to Gibbs phase rules by the coexistence of three phases during this transformation: the solid phase 1 , the solid phase 2 and the liquid phase. It is a peritectic-like transformation. ${ }^{32}$

In this regime of concentration, the second transition is observed by all techniques, at the same temperature, within a few degrees. This transition is a gel-to-sol transition, as clearly identified in rheology experiments by $G^{\prime}$ becoming inferior to $G^{\prime \prime}$. The diagram displays two liquidus, one below $39^{\circ} \mathrm{C}$ for gel 1 and one above for gel 2 . The curve of NMR intensities superimposes both. There is a gap at $39^{\circ} \mathrm{C}$ between both liquidus. The liquidus below $39^{\circ} \mathrm{C}$ corresponds to a higher solubility than the liquidus above $39^{\circ} \mathrm{C}$. The solid fraction in gel 2 is therefore less soluble than in gel 1 , and the sol below $39^{\circ} \mathrm{C}$ is supersaturated in regard to the sol above $39^{\circ} \mathrm{C}$. The gap between both liquidus is a hint that the sol and the gel below $39{ }^{\circ} \mathrm{C}$ are metastable. It will be studied more in detail in the next section. 


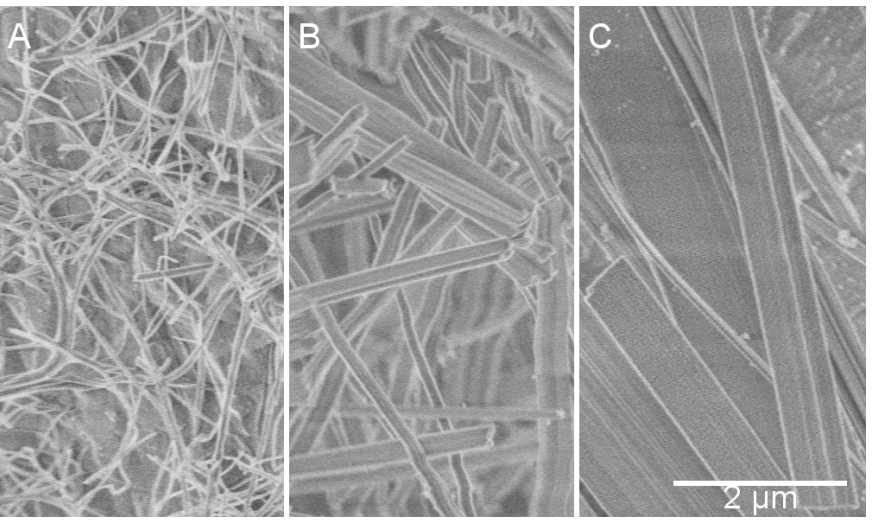

Figure 8. SEM micrographs of HUB-4/trans-decalin ( 2 wt. \%) formed at high cooling rate $\left(>5^{\circ} \mathrm{C} / \mathrm{min}\right.$ ). A: gel kept at $25^{\circ} \mathrm{C}, 20 \mathrm{~min}$ after its formation. B: same gel after annealing at $45{ }^{\circ} \mathrm{C}$ for $2 \mathrm{~h}$. C: gel kept at $25^{\circ} \mathrm{C}$ for 4 days.

\section{Structure and relative stability of both gels.}

As shown above, when the gel is heated above $40{ }^{\circ} \mathrm{C}$, it transforms into an opaque gel. A gel at 2 wt. \% was formed with high cooling rate and it was annealed $2 \mathrm{~h}$ at $45^{\circ} \mathrm{C}$. The temperature of $45^{\circ} \mathrm{C}$ falls in the domain of gel 2 , above the gel-to-gel temperature and below the melting temperature (Fig. 7). Two samples were taken from this gel: one short after the gel was formed, the other after annealing. Both have been observed by cryo-SEM after sublimation of the solvent and show different morphologies. (Fig. $8 \mathrm{~A}$ and B). The gel kept at $25{ }^{\circ} \mathrm{C}$ and observed shortly after its formation shows a network of fibrillar aggregates with diameters comprised between 25 and $81 \mathrm{~nm}$ (avg. $52.7 \pm 14.3 \mathrm{~nm}$ ). When the gel is annealed at $45^{\circ} \mathrm{C}$ for $2 \mathrm{~h}$, the thin fibrils are replaced by rigid fibers with widths comprised between 95 and $547 \mathrm{~nm}$ (avg. $280 \pm 94 \mathrm{~nm}$ ). This change in morphology is consistent with what is observed from OM. When the gel is not annealed and kept at $25^{\circ} \mathrm{C}$ for longer times, typically a few days, it becomes opaque. As shown by SEM (Fig $8 \mathrm{C}$ ), it contains the same kind of fibers than the annealed gel, with larger widths comprised between $200 \mathrm{~nm}$ and $1.1 \mu \mathrm{m}$ (avg. 500 $\pm 200 \mathrm{~nm}$ ). The aged gels and the annealed gels are structurally equivalent, which suggests that gel 1 is metastable and that gel 2 is the thermodynamically stable form.

This change of the morphology of the aggregates explains the change in elastic modulus of the samples visible in figure 4 . The elasticity depends both on the density of the nodes of the network and one the intrinsic stiffness of the aggregates. The nanotubes in gel 1 are thinner objects and are less rigid than the fibers in gel 2. However, a given amount of gelator forms more nanotubes than large fibers, and hence a higher density in nodes, which may explain a higher $G^{\prime}$ value at low $T$. The kinetics may modify this order because the amount of the fibers grows slowly and also because their thicknesses increase with time, especially when they ripen long enough (at low heating rates or by annealing). When the gel is heated at higher heating rate and without annealing, the fibers are thinner and $G^{\prime}$ may become slightly higher after the transition, as in Figure 3.

The structural difference between gels 1 and 2 becomes more evident when the samples are analysed by $\mathrm{X}$-ray scattering for $q$-values comprised between 0.011 and $1.90 \AA^{-1}$. In this experi-
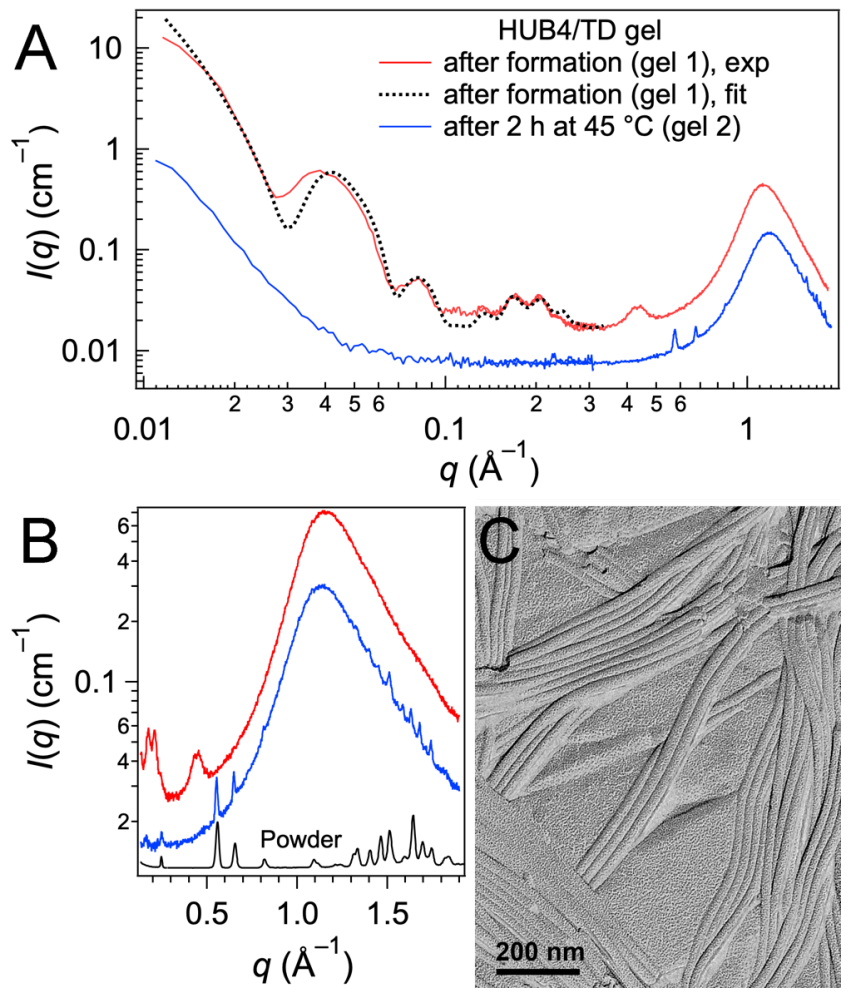

Figure 9. A: SAXS and WAXS intensities of a HUB4/TD gel (2 wt. \%) after formation and after annealing at $45{ }^{\circ} \mathrm{C}$. The fit was done according to ref. 26 . B: enlargement of WAXS q-range and comparison with the powder. $\mathrm{C}$ : Micrograph of a freeze fractured of a fresh HUB4/ $\mathrm{C}_{6} \mathrm{H}_{12}$ (2 wt. \%) showing nanotubes.

ment, the gel 1 was formed rapidly by quenching the hot solution at $10^{\circ} \mathrm{C}$ and it was kept at this temperature to slow its conversion in gel 2 . After measuring the scattered intensity, it was converted into gel 2 in situ by annealing at $40^{\circ} \mathrm{C}$ and the intensity was measured again. For the gel freshly formed (gel 1), the intensity shows a series of oscillations at low $q$-values. These oscillations correspond to the same form factor as for nanotubes formed by HUB-4 in cyclohexane, a solvent closely related to trans-decalin. ${ }^{26}$ Fits of the intensity with the same form factor yielded the same parameters within $1 \mathrm{~nm}$, especially an external radius of $19 \mathrm{~nm}$ and internal radius of $12 \mathrm{~nm}$. These nanotubes can be observed directly in cyclohexane by freeze fracture TEM (Fig. 9 C). The thinnest fibrils visible by SEM in fresh gels (Fig. 8A) can be attributed to single tubes, and the average-sized objects in this micrograph represent bundles of such tubes. At higher $q$ values, gel 1 shows no Bragg peaks. When the gel is transformed in gel 2, either by heat or ageing at RT, its characteristic oscillations at low $q$-values disappear. But at higher $q$-values, a series of Bragg peaks appear. The WAXS patterns of gel 2 were collected at varying temperatures, and all comprised up to 40 reflections, from 25 to $2 \AA$ in real space. It shows that the large aggregates in gel 2 are highly crystalline. The position of the scattering rings, after radial averaging, allows to resolve the crystalline lattice. The symmetry and the lattice parameters do not evolve much with temperature. Figure 10 shows the indexed radial profile measured at $45^{\circ} \mathrm{C}$. The low-angle region is composed of (i) two intense first order reflections $\left(0.2504 \AA^{-1}\right.$ and $0.5557 \AA^{-1}$ ) and (ii) a series of weaker higher order (hO/) re- 


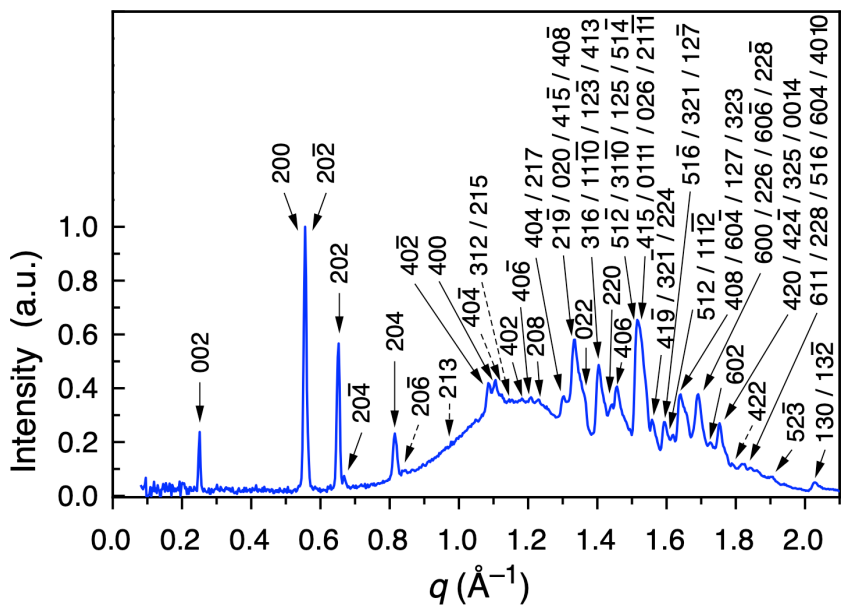

Figure 10. WAXS of HUB4/TD gel ( 2 wt. \%) annealed at $45^{\circ} \mathrm{C}$ (measurement on the SIRIUS beamline at SOLEIL synchrotron). The radial averaging scattering pattern is obtained from the $2 \mathrm{D}$ isotropic powder diffraction after background correction and solvent subtraction. The indexing ( $h k l$ indices on top of the peaks) lead to a centered monoclinic cell with $a=23.16(5) \AA$; $b=9.41(8) \AA$ 的 $c=51.19(8) \AA$; $\alpha=\gamma=90^{\circ}$ and $\beta=101.5(0)^{\circ}$.

flections, occurring from a bidimensional sub-lattice of oblique symmetry. The short and long edges of this sub-lattice are assigned to the $a$ and $c$-axes, with $a=23.16(5) \AA$ and $c=51.19(8)$ $\AA$, at an angle $\beta=101.5(0)^{\circ}$. The wide-angle region includes crossed reflections involving the periodicity along the $b$-axis, yielding the three-dimensional structure. The indexation converges on a crystal lattice of monoclinic symmetry. Because all the $(h k l)$ peaks have an even $h+k+l$ sum, the 3D lattice is centered. Furthermore, the systematic missing $(h 0 /)$ peaks with odd $h$ or odd / suggests that the oblique sub-lattice $\boldsymbol{a} \times \boldsymbol{c}$ is doubled relatively to the two-dimensional lattice. ${ }^{33}$ This doubling results from the 3D structure, which gives rise to $(h k l)$ reflections with $k \neq 0$, odd $h$ or odd $l$, and $h+k+l=2 n$. Thus, the peak positions of all samples can be indexed to a monoclinic lattice of the highest symmetry with the space group $C 2 / c$ according to:

$$
q_{\mathrm{hk} 1}=2 \pi\left[\left(\frac{h}{a \sin \beta}\right)^{2}+\left(\frac{k}{b}\right)^{2}+\left(\frac{l}{c \sin \beta}\right)^{2}-2 \frac{h l}{a c} \frac{\cos \beta}{\sin ^{2} \beta}\right]^{1 / 2}
$$

with 3D lattice constants, $a=23.16(5) \AA, b=9.41(8) \AA$ and $c=$ 51.19(8) $\AA$, and angles $\alpha=\gamma=90^{\circ}$, and $\beta=101.5(0)^{\circ}$. To summarize, the aggregates in the gel 2 yield a well-resolved diffraction pattern, corresponding to well-defined crystalline structure. The gel freshly formed (gel 1) and the gel annealed above $40{ }^{\circ} \mathrm{C}$ (gel 2) have also different FTIR spectra (Fig. 11). The amide I band shifts from 1636 to $1639 \mathrm{~cm}^{-1}$, the amide II band from 1548 to $1539 \mathrm{~cm}^{-1}$ and the $\mathrm{NH}$ stretching band from 3307 to 3303 $\mathrm{cm}^{-1}$. These shifts show that in both gels, the amides groups are all $\mathrm{H}$-bonded with each other, but with different pattern of the bonds. Other bands, the ester $\mathrm{CO}$ stretching band and the aromatic stretching bands, also shift, reflecting a different array of the corresponding groups in both gels. All the bands before annealing are broader before annealing than after. The broad bands show that in gel 1 the vibration modes are more dispersed, which suggests several kinds of $\mathrm{H}$-bonds between the amide groups. It may also reveal a more ordered packing of the amide groups in gel 2 than in gel 1. The FTIR spectrum of a sample aged at $25^{\circ} \mathrm{C}$ for one week, is the same as after annealing,

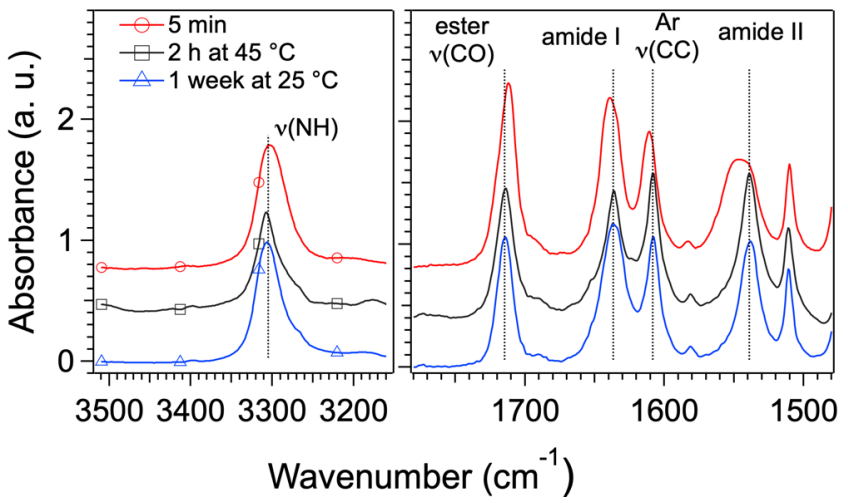

Figure 11. FTIR spectra of a gel of HUB-4 in TD ( $2 \mathrm{wt} . \%)$, formed upon rapid cooling after, heated at $45{ }^{\circ} \mathrm{C}$ or after one week at $25^{\circ} \mathrm{C}$. Left: $\mathrm{NH}$ stretching area. Right: carbonyl stretching area.

confirming that gel 1 is metastable and slowly transforms into gel 2.

The presence of one or two transitions depends on the thermal history of the sample. In a simple DSC experiment, gels were formed at different cooling rates; then they were let at $15^{\circ} \mathrm{C}$ for $70 \mathrm{~min}$ and their thermograms were measured upon heating at $0.25^{\circ} \mathrm{C} / \mathrm{min}$ (Fig. 12). When the gel is formed faster, the first transition is present and when the gel is formed slowly and when it is annealed or aged, only the second transition appears. This difference of kinetics can also explain why the gel-to gel transition is observed only above a threshold concentration ( 1 wt. \%). The kinetics of formation of both gels depend on concentration and on the supersaturation. At low concentration, the nanotubes form first, which lowers the concentration of gelator in solution and keeps the rate of formation of the fibers negligible. Only above a sufficient supersaturation this formation competes with that of the nanotubes and both aggregates can form. Since their formations also depend on nucleation, the relative amount of both aggregates may vary from one experiment to the other, even when the gel is formed in the same conditions.

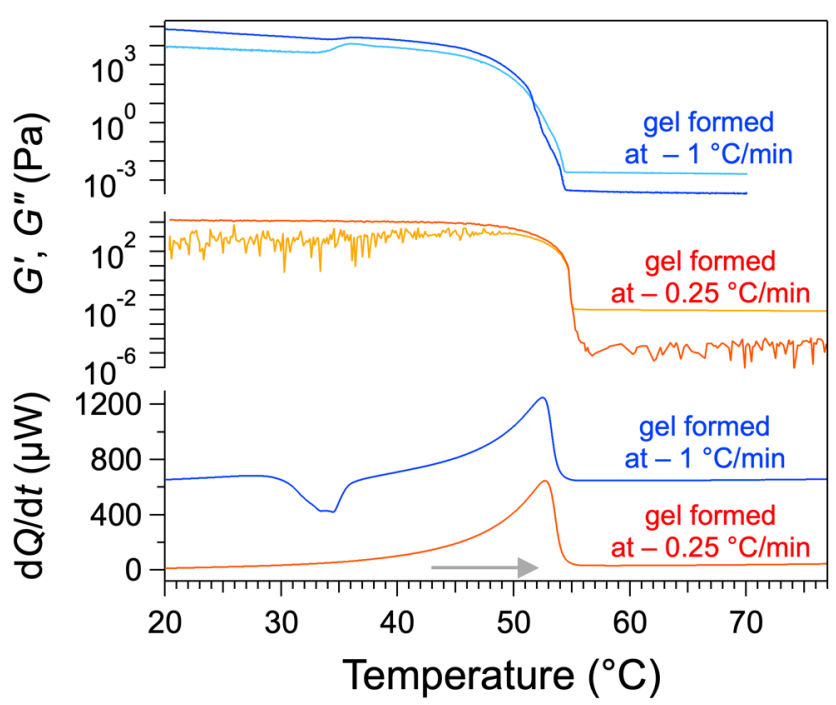

Figure 12. Thermograms upon heating of gels of HUB-4/trans-decalin (2 wt. \%) formed at different cooling rates and corresponding rheological measurements. Heating rate: $0.25^{\circ} \mathrm{C} / \mathrm{min}$ for all experiments. Thermograms have been shifted for clarity. 


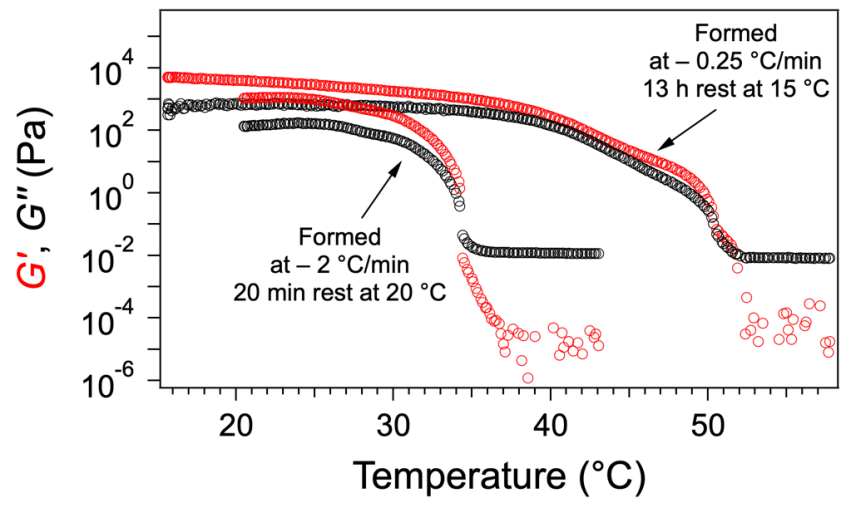

Figure 13. Comparison of the elastic and viscous moduli of the same HUB-4/trans-decalin sample ( $0.5 \mathrm{wt}$. \%) gelled at low and fast cooling rates.

By choosing the conditions of cooling rate, aging duration or annealing, one can change the rheological response of the gel. This is illustrated when the mechanical response is measured on a gel formed at a fast rate $\left(2^{\circ} \mathrm{C} / \mathrm{min}\right)$ and the same gel formed by cooling at a slower rate $\left(0.25^{\circ} \mathrm{C} / \mathrm{min}\right)$ down to $15^{\circ} \mathrm{C}$ and let rest for $13 \mathrm{~h}$ at this temperature. When the sample is cooled fast and not matured, it melts at $34{ }^{\circ} \mathrm{C}$, on the first liquidus (Fig. 13). When it is cooled slowly and let rest for $13 \mathrm{~h}$, it melts at $50{ }^{\circ} \mathrm{C}$, on the second liquidus.

To summarize, the formation of one of the forms depends on the rate of cooling during the formation of the gel and on the age of the gel. Such a dependence of the morphology on the cooling rate has been observed, by Lescanne et al. ${ }^{22}$ This is not always the case: as shown by Liu et al., ${ }^{34}$ the cooling rate has no influence on the morphology of the aggregates (fibers or spherulites) in the gels formed by a lysine derivative, but the relevant parameter is supersaturation. Weiss et al. ${ }^{19}$ have also shown that the temperature at which the gel is formed controls the morphology of the aggregates. In the present study, nanotubes are the self-assemblies formed kinetically but are metastable. As shown by Gubitosi et al. ${ }^{35}$, kinetically stable tubes formed by a lithocholate derivative are thermodynamically metastable. Similar to HUB-4, they transform into crystals above a given temperature or upon aging. The phase diagrams are similar, especially with a higher solubility of the nanotubes than the crystals. In both systems, the nanotubes form kinetically and are not frozen and evolve, likely via an equilibrium with the soluble fraction, toward other species.

\section{Conclusion}

We have shown how the polymorphism of an organogel impacts its $c$ - $T$ phase diagram. It results in a gel-to-gel transition that occurs above a threshold concentration, and at a constant temperature. This transition is attributed to a peritectic transformation. Such a transition, common in other domains of chemistry, is now also encountered in organogels. We have proved that the gel existing below the transition temperature is metastable. Therefore, the nanotubes composing it are not thermodynamically stable. They can exist, despite their instability, because they form much faster than the thermostable crystallites.
This difference of rates is probably driven by a different $\mathrm{H}$-bonding pattern.

\section{Conflicts of interest}

There are no conflicts to declare.

\section{Author contributions}

Conceptualization, N. P. D.-Z., P. J. M. methodology, A. C., J. C., D. C., L. J., P. K, B. H; formal analysis, D. S., S. Z.-C., J. C., D.C, P. K., B.H.; investigation, D. S, S. Z.-C., A. C., J. C., D. C., L. J., P. K., B. H., J.-P. L., E. W.; resources, P. J. M. and N. P. D.-Z; writingoriginal draft preparation, P. J. M.; writing-review and editing, D. S., S. Z.-C., J. C., D. C., P. K., N. P. D.-Z., P.J.M.; visualization, D. S., J. C., D. C., P. K., P. J. M.; supervision, N. P. D.-Z. and P. J. M.; funding acquisition, N. P. D.-Z.

\section{Acknowledgements}

Guillaume Fleith is acknowledged for the SAXS and WAXS measurements. The ICS characterization facility and Anaïs de Maria are acknowledged for the FTIR measurements. Tecnológico Nacional de México and CONACyT are acknowledged for Ph. D. grant number 419345 (S. Z.-C.). The Agence National de la Recherche and the Indo-French Centre for the Promotion of Advanced Research are acknowledged for their financial support (Grant IFCPAR-CEFIPRA (DST)-ANR 14-CE08-0020-01. Marc Schmutz is acknowledged for helpful discussions. Emeric Wasielewski is acknowledged for the VT-NMR experiments. D. S is supported by fellowship of the French Department of High Education and Research (MESR, ED 182). We thank SOLEIL synchrotron for beamtime provision and A. Hemmerle, P. Fontaine, N. Aubert for technical help. Synchrotron experiments were carried out within the framework of the MICASOL platform set between Institut Charles Sadron, C.N.R.S., Strasbourg, France, and SOLEIL synchrotron (www.ics-cnrs.unistra.fr/micasol).

\section{Notes and references}

1 M. George and R. G. Weiss, in Molecular Gels, eds. R. G. Weiss and P. Terech, Springer Netherlands, 2006, pp. 449-551.

2 R. G. Weiss, Molecular Gels, The Royal Society of Chemistry, 2018.

3 F. Fages, Ed., Low Molecular Mass Gelators - Design, Self-Assembly, Function, Springer Berlin Heidelberg, Berlin, Heidelberg, 2005, vol. 256.

4 A. R. Hirst, B. Escuder, J. F. Miravet and D. K. Smith, Angew. Chem. Int. Ed. Engl., 2008, 47, 8002-8018.

5 X. Du, J. Zhou, J. Shi and B. Xu, Chem. Rev., 2015, 115, 1316513307.

6 S. S. Babu, S. Prasanthkumar and A. Ajayaghosh, Angew. Chem. Int. Ed., 2012, 51, 1766-1776.

7 R. G. Weiss, J. Am. Chem. Soc., 2014, 136, 7519-7530.

8 K. Hanabusa, M. Matsumoto, M. Kimura, A. Kakehi and H. Shirai, J. Colloid Interface Sci., 2000, 224, 231-244.

9 P. Curcio, F. Allix, G. Pickaert and B. Jamart-Grégoire, Chem. Eur. J., 2011, 17, 13603-13612. 
10 M. Raynal and L. Bouteiller, Chem. Commun., 2011, 47, 82718273.

11 J. Bonnet, G. Suissa, M. Raynal and L. Bouteiller, Soft Matter, 2014, 10, 3154-3160.

12 Y. Lan, M. G. Corradini, X. Liu, T. E. May, F. Borondics, R. G. Weiss and M. A. Rogers, Langmuir, 2014, 30, 14128-14142.

13 L. Feng and K. A. Cavicchi, Soft Matter, 2012, 8, 6483-6492.

14 E. Christ, C. Blanc, A. Al Ouahabi, D. Maurin, R. Le Parc, J.-L. Bantignies, J.-M. Guenet, D. Collin and P. J. Mésini, Langmuir, 2016, 32, 4975-4982.

15 J. H. van Esch, F. Schoonbeek, M. de Loos, H. Kooijman, A. L. Spek, R. M. Kellogg and B. L. Feringa, Chem. - Eur. J., 1999, 5, 937-950.

16 A. R. Hirst, I. A. Coates, T. R. Boucheteau, J. F. Miravet, B. Escuder, V. Castelletto, I. W. Hamley and D. K. Smith, J Am Chem Soc, 2008, 130, 9113-21.

17 T. Guterman, M. Levin, S. Kolusheva, D. Levy, N. Noor, Y. Roichman and E. Gazit, Angew. Chem. Int. Ed., 2019, 58, 15869-15875.

18 X. Huang, P. Terech, S. R. Raghavan and R. G. Weiss, J. Am. Chem. Soc., 2005, 127, 4336-4344.

19 X. Huang, S. R. Raghavan, P. Terech and R. G. Weiss, J. Am. Chem. Soc., 2006, 128, 15341-15352.

20 H. Xie, M. A. Ayoubi, W. Lu, J. Wang, J. Huang and W. Wang, Sci. Rep., 2017, 7, 1-6.

21 A. Kotlewski, B. Norder, W. F. Jager, S. J. Picken and E. Mendes, Soft Matter, 2009, 5, 4905-4913.

22 M. Lescanne, A. Colin, O. Mondain-Monval, F. Fages and J. L. Pozzo, Langmuir, 2003, 19, 2013-2020.

23 A. Meister, S. Drescher, V. M. Garamus, G. Karlsson, G. Graf, B. Dobner and A. Blume, Langmuir, 2008, 24, 6238-6246.

24 R. Koningsveld, R. Koningsveld, W. H. Stockmayer and E. Nies, Polymer Phase Diagrams: A Textbook, Oxford University Press, 2001.

25 A. D. Pelton, Ed., Phase Diagrams and Thermodynamic Modeling of Solutions, Elsevier, Amsterdam, 2019.

26 S. Zapién-Castillo, N. P. Díaz-Zavala, J. A. Melo-Banda, D. Schwaller, J.-P. Lamps, M. Schmutz, J. Combet and P. J. Mésini, Int. J. Mol. Sci., 2020, 21, 4960.

27 E. Christ, D. Collin, J.-P. Lamps and P. J. Mésini, Phys. Chem. Chem. Phys., 2018, 20, 9644-9650.

28 P. Fontaine, G. Ciatto, N. Aubert and M. Goldmann, Sci. Adv. Mater., 2014, 6, 2312-2316.

29 F. Placin, J.-P. Desvergne and J.-C. Lassègues, Chem. Mater., 2001, 13, 117-121.

30 J.-P. Desvergne, T. Brotin, D. Meerschaut, G. Clavier, F. Placin, J.-L. Pozzo and H. Bouas-Laurent, New J. Chem., 2004, 28, 234-243.

31 P. Terech, C. Rossat and F. Volino, J. Colloid Interface Sci., 2000, 227, 363-370.

32 M. Hillert, in Phase Equilibria, Phase Diagrams and Phase Transformations, Cambridge University Press, Cambridge ; New York, 2nd edition., 2007, pp. 253-278.

33 T. Hahn, International Tables for Crystallography, WileyBlackwell, Dordrecht, Volume A, 5th Edition., 2005.

34 R. Wang, X.-Y. Liu, J. Xiong and J. Li, J. Phys. Chem. B, 2006, 110, 7275-7280.

35 M. Gubitosi, A. D'Annibale, K. Schillén, U. Olsson, N. V. Pavel and L. Galantini, RSC Adv., 2016, 7, 512-517. 